\title{
Recurrent laryngeal nerve
}

\author{
Bulent Yalcin · Yavuz Poyrazoglu
}

Received: 14 February 2012/ Accepted: 24 March 2012/Published online: 5 April 2012

(C) Springer-Verlag 2012

We read with interest the article stated by Tang et al. [3] concerning anatomical study on the recurrent laryngeal nerve (RLN) and inferior thyroid artery (ITA). Our comments are as follows:

- Instead of the term 'anus perineum', the term 'inferior pole of the thyroid gland' is more understandable.

- The authors stated that 'before entering the larynx, the RLN divided into anterior and posterior branches in $147 / 160$ sides,... the later innervating the posterior cricoarytenoid and thyroarytenoid muscles'. It is stated in the textbook [2] and the article [1] that 'the anterior branch is mainly motor..., and the posterior branch is mainly sensory. Actually, we have expected to learn how the authors identify the posterior one innervates, the muscles mentioned above. Have the branches been followed to the muscles in the larynx, or stimulated by a neurostimulator, or etc.? Information about it should be given.

- In the Fig. 1, it is clearly seen that the RLN divides into two branches, large and thin. The latter one, not RLN, also divided into two branches. The authors claimed that 'the Fig. 1 has three branches according to its different destination.' Number of the branches of the RLN should be described according to their origin points on the main trunk of the RLN. It should not be named according to their destination.

B. Yalcin $(\bowtie)$

Department of Anatomy, Gulhane Military Medical Academy, 06018 Ankara, Turkey

e-mail: drbyalcin@yahoo.com; byalcin@gata.edu.tr

\section{Y. Poyrazoglu}

Department of Surgery, Elazig Military Hospital, Elazig, Turkey
- This study is an anatomical one investigating morphology of the RLN and ITA with their branches in cadavers. Although detailed knowledge about number of the branches and some measurements related to them has been given, some important knowledge about the multiple branches has not been mentioned. The authors claimed that their study is an applied anatomical study of the RLN, especially for thyroid surgery, but not systematical anatomy. Because of that, they did not focus on the multiple branches. Nevertheless, these branches may be very important during surgery. For example, a surgeon may confuse sensory and motor branches and save a sensory branch instead of a motor one. Damage of a sensory branch has no immediate critical outcome, but a section of a motor one causes a laryngeal paralysis, which can lead to suffocation if bilateral.

- Although the authors stated that the double RLNs were present in four sides, they stated only one sentence about it. Detailed knowledge about this kind of variation should help a surgeon identify unusual branching pattern around the inferior pole of the thyroid gland during surgery.

\section{References}

1. Kandil E, Abdelghani S, Friedlander P, Alrasheedi S, Tufano RP, Bellows CF, Slakey D (2011) Motor and sensory branching of the recurrent laryngeal nerve in thyroid surgery. Surgery 150(6): 1222-1227

2. Standring S (ed) (2005) Larynx. In: Gray's Anatomy, 39th edn. Elsevier Churchill Livingstone, Edingburgh, p 644

3. Tang WJ, Sun SQ, Wang XL, Sun YX, Huang HX (2011) An applied anatomical study on the recurrent laryngeal nerve and inferior thyroid artery. Surg Radiol Anat (published online) 